\title{
Acompañamiento como metodología de Trabajo Social en tiempos de cólera
}

\section{Accompaniment as Social Work methodology in cholera times}

\author{
Esther RAYA DÍEZ \\ Universidad de La Rioja \\ esther.raya@uniroja.es \\ Neus CAPARrós Civera \\ Universidad de La Rioja \\ caparros@uniroja.es
}

Recibido: 01/08/2013

Revisado: 05/08/2013

Aceptado: 18/02/2014

Disponible on line: $27 / 06 / 2014$

\section{Resumen}

En el artículo se presenta el acompañamiento como metodología del Trabajo Social, que trata de dar respuesta a las necesidades y problemas sociales en un contexto fuertemente marcado por la crisis económica, con la agudización de los problemas sociales y la pérdida de intensidad de las políticas públicas en materia social. Ello está generando un cambio en el rol profesional, ante la insuficiencia, cuando no carencia de recursos. El artículo se estructura en tres partes: a) en la primera se parte de una mirada al trabajo social actual, la profesión vive momentos de cólera, rabia, impotencia ante la presión que sobre el sistema de servicios sociales se está produciendo, por el incremento de las situaciones de necesidad y por el recorte de los presupuestos en gasto social; b) en la segunda parte, se presenta la convicción de que el acompañamiento es la metodología propia del Trabajo Social, basada en la relación de ayuda. Se describe la metodología del acompañamiento y los métodos y técnicas de intervención aplicados a la relación de ayuda, que posibilitan el cambio de rol del profesional de gestor de recursos a generador de recursos; c) en la tercera parte se realiza una reivindicación a favor de un trabajo social orientado por la investigación y el contraste teórico-práctico de la intervención en la realidad social.

Palabras clave: acompañamiento, incorporación social, participación, inclusión social, exclusión social.

\begin{abstract}
Accompaniment is presented as a method of social work, which attempts to respond to the needs and social problems in a context strongly marked by the economic crisis, the worsening social problems and fading of public policy on social matters. This is causing a change in the professional role, to the failure, if not lack of resources. The article is structured in three parts: a) the first part of looks at the current social work profession, which lives moments of anger, rage, powerlessness pressure on the social services system, by the increase situations of need and by trimming budgets in social spending; b) in the second part, is presented the conviction that the accompaniment is the methodology of social work, based on the aid relationship. Is described accompanying methodology and intervention methods and techniques applied to the helping relationship, which enable the changing role of the professional resource manager to resource generator; c) In the third part, a claim is made for a social work oriented to research and to contrast theoretical and practical intervention in social reality.
\end{abstract}

Keywords: support guidance, social incorporation, participation, social inclusion, social exclusion.

Referencia normalizada: Raya Díez, E., y Caparrós Civera, N. (2014): «Acompañamiento como metodología de Trabajo Social en tiempos de cólera». Cuadernos de Trabajo Social, 27(1): 81-91.

Sumario: 1. Trabajo Social en tiempos de cólera. 2. Acompañamiento para la incorporación social. 3. Algunas técnicas que posibilitan el acompañamiento. 4. Consideraciones finales. 5. Referencias bibliográficas. 


\section{Trabajo Social en tiempos de cólera ${ }^{1}$}

Vivimos tiempos de cólera, de rabia y enojo. Tiempos de desánimo. La crisis ha dejado de ser noticia para convertirse en una triste cotidianeidad. La burbuja (inmobiliaria) en la que estábamos instalados ha pinchado, llevándose por delante, en efecto dominó, a muchos efectivos, Y, como las epidemias de cólera de otros tiempos y otros lugares azota a quienes están en peor posición social o en situación de vulnerabilidad. Mientras la vida se sucede, continúa, transcurre en paralelo a las historias personales, de amor y desamor como en el novela de García Márquez.

En los últimos años la sociedad líquida ha evidenciado la pérdida de vínculos sociales. Las sociedades occidentales con fuerte arraigo de sistemas de protección social han contado con sólidas estructuras de integración que hacían a la persona menos vulnerable y, por lo tanto, menos dependiente de sus relaciones interpersonales. La actual situación de crisis donde se liquidan los mecanismos fuertes de integración: empleo, vivienda e ingresos, está llevando a la solidificación de los vínculos sociales como forma de respuesta (y de supervivencia) para afrontar el rigor de las condiciones sociales de los grupos más vulnerables, en situación o riesgo de exclusión.

El cólera es una enfermedad infecto-contagiosa que se transmite a través del agua o de los alimentos. El desánimo también se transmite por contagio, por pérdida de ilusión y de confianza en la capacidad individual y colectiva de producir cambios. Cuando el cólera llega a los profesionales del Trabajo Social, que en los manuales clásicos se definen como «agentes de cambio», debemos preocuparnos. Preocuparnos. Revisar cuáles son nuestros marcos teóricos y metodológicos, nuestra misión y visión, nuestro papel en los procesos de intermediación social con las personas, familias, grupos y comunidades con las que trabajamos.

La extensión del Estado de bienestar ha permitido la consolidación profesional del Trabajo Social a través de los Servicios Sociales. Hemos vivido décadas de burbuja de recursos. Y ahora la crisis está pasando factura ¿cómo gestionar sin recursos? Y la historia reciente hace olvidar la más lejana, la de los orígenes del Trabajo Social, la del profesional de referencia y la relación de ayuda como recurso. La de soluciones innovadoras y creativas como respuesta a los problemas de hacinamiento, pobreza, falta de ingresos o problemas de salud.

La crisis como oportunidad es una frase que se repite frecuentemente. Puede ser interpretada como miserere para quien no tiene consuelo, o como orientación para quien confía en su capacidad de producir cambios. Tras el tsunami con sus efectos devastadores, solo queda reorganizar y corregir para prevenir las consecuencias negativas de movimientos similares en el futuro. La sociedad que está configurándose en el nuevo estadio, no será la de finales del siglo XX. Las necesidades sociales reclamaran nuevas formas de intervención a los profesionales del Trabajo Social, que no pueden quedarse atrapados por las aguas contaminadas del cólera o los muros derribados del tsunami.

La Agenda Global para el Trabajo Social es un instrumento aprobado por las tres organizaciones internacionales que representan a los ámbitos educativos y profesionales del Trabajo Social. Es una oportunidad para redefinir los marcos de trabajo y de intervención. La Agenda Global tiene como finalidad promover la equidad económica y social, a través de la colaboración con Naciones Unidas y otros organismos internacionales, señalando su compromiso con la promoción de igualdades sociales y económicas; la garantía de la dignidad y valía de la personas; la promoción de la sostenibilidad en las comunidades y desarrollo medioambiental; promoción del bienestar a través de las relaciones humanas; $y$, garantía de un ambiente apropiado para la práctica y la educación. Estas acciones, definidas a nivel macrosocial de las organizaciones del Trabajo Social, deben tener su correlato en el entorno micro en el que se desenvuelve el quehacer cotidiano de los trabajadores y trabajadoras sociales.

Por ello, consideramos importante su vinculación con los procesos de innovación social.

Innovación, mejora, cambio. Se trata de buscar nuevas fórmulas de actuación en nue-

${ }^{1}$ Una primera versión de este epígrafe se publicó como Tribuna del periódico La Rioja, el 24/03/2013 y en la página web de la Universidad de la Rioja, con motivo de la celebración del Día Mundial del Trabajo Social en 2013. Disponible en: https://www.unirioja.es/apnoticias/servlet/Archivo?C_BINARIO=4572 
vos contextos sociales, económicos y políticos. La innovación social es una realidad «en construcción», como se define en una de las múltiples páginas web de consultorías especializadas en este nuevo escenario. Una de las conclusiones de las VI Jornada Anual del Instituto de Innovación Social de ESADE puede resumirse en la siguiente frase: «Si quieres viajar rápido, viaja solo. Si quieres llegar lejos, viaja acompañado». La innovación social busca la colaboración de todos los actores, en particular administraciones, empresas, tercer sector y sociedad civil para fortalecer los entornos. Es un nuevo ámbito de creación, desarrollo o difusión de nuevas prácticas sociales, buscando una suma positiva de actores para el desarrollo económico y social sostenible en un contexto glocal.

La lucha contra el cólera implica una acción decidida que va más allá de la profilaxis o tratamiento individual, requiere la colaboración de los diferentes actores, a través de medidas de sanidad pública y de educación a la población, para evitar la propagación de los brotes. En todo caso, se entiende que es necesaria la intervención de los profesionales sanitarios para una adecuada respuesta. En los procesos de innovación social que están surgiendo en los últimos años, es necesaria la actuación de los trabajadores sociales, en un nuevo rol de emprendedores sociales. La cuestión es ¿estamos preparados para este nuevo reto? ¿estamos dispuestos a desempeñarlo?

\section{Acompañamiento para la incorporación social}

Los nuevos escenarios que se están dibujando con la prolongación de la crisis económica y el modelo (social) europeo están produciendo una fuerte presión en el sistema de Servicios Sociales, que debe afrontar un doble reto difícilmente conciliable. Por un lado, atender a un mayor volumen de población, con problemas relacionados con la exclusión y la vulnerabilidad; y, por otro lado, gestionar con menor volumen de recursos. En este contexto, se hace preciso recuperar el rol de generador de recursos frente al de gestor de recursos, que ha sido el prevalente durante el desarrollo del Estado de bienestar.

El acompañamiento, como metodología de intervención social, permite orientar la acción profesional hacia procesos de cambio, con la persona y con el entorno. Hablar de acompañamiento es hablar de Trabajo Social. Tal y como lo definen Funes y Raya (2001), acompañar es avanzar «al lado de». Avanzar «al lado de» es compartir un proyecto común.

Acompañar es mirar de otra manera a la persona y su historia, para que ella pueda verse de otra forma. Es creer en sus potencialidades, ayudarle a tomar conciencia y a desarrollarse, sea cual sea su estado actual. Acompañar es mediar entre las instituciones, más o menos burocratizadas de una sociedad y las personas que, por estar excluidas no puedan hacer valer sus derechos (p. 33).

El acompañamiento, como metodología, permite trazar un proyecto con la persona, teniendo en cuenta el punto de partida y las condiciones del contexto (económicas, políticas, sociales, culturales, etc.) que actuaran como factores de riesgo o de protección. Se debe tener en cuenta que acompañar no es lo mismo que

Dirigir o tutelar, ni que «llevar», ni que atender de forma puntual. Supone también reconocer el protagonismo de los sujetos en el desarrollo de su proceso, y situarse en la posición de quien está al lado a lo largo de un período, aportando elementos que ayuden al sujeto a desarrollarse (Aguilar y Llobet, 2010, p. 20).

Por lo tanto, el acompañamiento es una metodología para trabajar la relación social y educativa que implica el proceso de incorporación social con personas en situación de vulnerabilidad o exclusión. Es una forma de trabajar utilizando los recursos, métodos y técnicas, desde un pluralismo metodológico, con la finalidad de facilitar el desarrollo personal y la promoción de la autonomía del sujeto en un proceso de cambio. El acompañamiento, es una forma de entender la relación entre el profesional y la persona atendida, en una relación horizontal, donde el profesional se sitúa en una posición de ayuda, orientación, apoyo y no de control.

El acompañamiento, como metodología, se utiliza en diferentes ámbitos de la intervención social, con menores, drogodependientes (Funes, 1995; Arjona, 2004; Nogués, 2007; Arjona, 2008). El objeto de nuestro trabajo se centra en el acompañamiento en procesos de inclusión social. Ello implica, en primer lugar, 
determinar qué tipología de usuarios es susceptible de formar parte de un programa de acompañamiento. A pesar del avance realizado en las ciencias sociales en torno al concepto de exclusión y su medida, todavía es necesario precisar más los instrumentos que aporten herramientas clave para los procesos de intervención social, tal y como hemos puesto de manifiesto en trabajos anteriores (Raya, 2010; Raya y Caparrós, 2013) Desde el punto de vista de la aplicación práctica del Trabajo Social, se trata de promover el acompañamiento con personas autónomas respecto a su proceso vital o susceptibles de llegar a serlo. Entre la población vinculada a los Servicios Sociales existen una diversidad de situaciones que no son abordables directamente por el acompañamiento, como por ejemplo, la intervención con menores, malos tratos, o salud mental, por citar algunos ejemplos. El acompañamiento debe promover la autonomía de la persona en los procesos de cambio en aquellos ámbitos vitales afectados en mayor medida en los procesos de exclusión.

Entre las razones que se pueden esgrimir a favor de utilizar el acompañamiento como metodología en los procesos de incorporación social, se puede señalar al menos tres. En primer lugar, los procesos de exclusión social son más complejos que los de pobreza, que afecta a la dimensión económica principalmente. La exclusión afecta a una multiplicidad de ámbitos vitales, se caracteriza por la multidimensionalidad y el dinamismo, lo que requiere intervenciones globales. En segundo lugar, cada vez es más frecuente encontrarse en los Servicios Sociales de Atención Primaria con un perfil de población «normalizado», afectado por procesos de movilidad descendente, como consecuencia de la larga duración de la crisis. En tercer lugar, se trata de evitar la cronificación de la exclusión, lo que requiere la puesta en marcha de intervenciones integrales, como señalan Funes y Raya «construir conjuntamente con otros profesionales formas de trabajo menos parcializadas y más integradoras» (2001), es decir, poner en marcha procesos y procedimientos de Trabajo Social.

En este sentido, se puede señalar que en los procesos de incorporación social no basta con la oferta de recursos y prestaciones. Estos son instrumentos, medios de un trabajo global con la persona, que implica que alguien, de forma personalizada facilite un estímulo, dé un primer empuje, haga sentir a la persona que puede ser, que funcionar socialmente es posible. Se trata de ofrecer el apoyo que las personas en situación o riesgo de exclusión necesitan para dar el paso, para imaginarse en opción (real) de cambio. Para recorrer este camino se pueden utilizar diferentes recursos (económicos, de empleo, de salud, culturales, deportivos, etc.) el nexo de unión de todos ellos, es el acompañamiento, donde el profesional desarrolla un rol de facilitador del proceso. Todo este proceso se sustenta en la voluntariedad, en la aceptación de la capacidad del sujeto para discernir sobre sus opciones vitales, en la aplicación del principio de autodeterminanción.

Las acciones para la incorporación social en cada persona cobran sentido en la medida que se han discutido, elaborado, rehecho, dentro de un itinerario personal que se ha ayudado a definir. Son acciones y experiencias que sólo cobran sentido dentro de un proceso. En algunos casos, el camino a recorrer es sencillo, en otros necesitará más tiempo, en función de la trayectoria recorrida y del punto de partida. En esos casos, el acompañamiento (o trabajo social) será más intenso, se trataría de una unidad de vigilancia intensiva (UVI) de Trabajo Social.

Como se ha señalado anteriormente se trata de acompañar a la persona en un proceso vital de cambio, podemos afirmar que la incorporación no es un punto de llegada fijo e igual para todas las personas. En todo caso, se podría definir, como lo hacen Aguilar y Llobet (2010), como,

El desarrollo personal, la integración comunitaria y el acceso a mecanismos de inserción social. Dicha atención requiere como principio centrarse en la persona y su contexto social y en la gestión de los procesos de incorporación, más que en la gestión de prestaciones y recursos (p. 20).

Por lo tanto, los elementos que definen un estado de incorporación hacen referencia a aspectos tales como los señalados por Funes y Raya (2001): a) Balance de experiencias y prácticas vitales mínimamente satisfactorio, que conduzca a la persona a un nivel razonable de aprecio y confianza en sí misma; b) Una cierta cantidad de relaciones sociales que le hagan llegar a sentirse parte de la comunidad; c) Conocimiento y aceptación de las normas y 


\begin{tabular}{|c|c|}
\hline Eje participación activa & Eje acompañamiento \\
\hline $\begin{array}{l}\text { Desarrollo personal e } \\
\text { itinerario } \\
\text { Sujetos con capacidad } \\
\text { de actuar } \\
\text { El sujeto como prota- } \\
\text { gonista del proceso }\end{array}$ & $\begin{array}{l}\text { Define la posición de } \\
\text { los intervinientes en } \\
\text { relación con los suje- } \\
\text { tos en dificultad }\end{array}$ \\
\hline $\begin{array}{l}\text { Proceso o itinerario } \\
\text { Partir de las capacida- } \\
\text { des } \\
\text { Fases (idas y venidas) } \\
\text { Protagonismo del su- } \\
\text { jeto } \\
\text { Co-Diagnóstico } \\
\text { Co-Determinación del } \\
\text { proceso } \\
\text { Co-producción de la } \\
\text { atención }\end{array}$ & $\begin{array}{l}\text { Gestión del caso (Tra- } \\
\text { bajo social con casos) } \\
\text { Proximidad activa } \\
\text { Proximidad construi- } \\
\text { da } \\
\text { Proximidad existen- } \\
\text { cial }\end{array}$ \\
\hline
\end{tabular}

Cuadro 1. Procesos de acompañamiento y ejes. Fuente: Elaboración propia, a partir de Aguilar y Llobet, 2010, pp. 22-25.

culturas básicas de la comunidad en la que se incorpora (p. 27). Es importante poner el acento que esto implica fijarse en los cambios conseguidos y no en las expectativas y deseos «prefijados» como estándar de una sociedad de bienestar como modelo único de integración.

En los procesos de incorporación los dos ejes relevantes son la participación y el acompañamiento, como se muestra en el Cuadro 1.

El eje de participación activa conecta con la idea del desarrollo personal del sujeto y la puesta en marcha de un itinerario para el logro de los objetivos. Esto implica que el sujeto tiene capacidad de actuar y llevar a cabo las acciones planteadas, siendo el protagonista del proceso. El complemento de la participación activa es el acompañamiento, por medio del cual se ofrece una relación de ayuda que orienta y guía al sujeto en el proceso de cambio. Como destacan Aguilar y Llobet (2011), «tal proceso de desarrollo personal solo puede estar protagonizado por el propio sujeto, aunque para ello necesite de apoyos y de acompañamiento» (p. 21).

En el eje de participación los autores insisten en el protagonismo del sujeto, a través del co-diagnóstico, que implica renunciar a la visión tecnocrática y establecer que la identificación debe hacerse de común acuerdo; la co-de- terminación del proceso, reforzando la idea del diseño conjunto de las acciones a realizar; y, la coproducción de la atención, tanto en el establecimiento de tareas y acciones a realizar en el plan de trabajo personal, como valorando la aportación que las personas atendidas pueden hacer a su propio proceso, al de otros y a la colectividad. Con ello el sujeto adquiere un rol de actor, de productor de cambios, y no solo de receptor de prestaciones.

Por su parte, el eje de acompañamiento incluye varios elementos, partiendo de la gestión de caso, introduce tres dimensiones en torno al concepto de proximidad. En primer lugar, la proximidad activa, entendida como la disposición de «ir a buscar a las personas en dificultad allá donde se encuentran»; la proximidad construida, se refiere a la «creación o construcción de vínculos de cercanía y confianza entre personas en dificultad e intervinientes sociales» y en tercer lugar, la proximidad existencial, se refiere «al papel de las personas en dificultad en la atención de personas en dificultad» (p. 25). Con esta última idea los autores refuerzan el papel activo del sujeto y conectan con el concepto de ciudadanía social.

El proceso de incorporación, entendido como proceso de cambio, implica un principio y un fin. Conviene establecer periodos de tiempo, conforme a los cuales establecer hipótesis de cambio. Es más fácil imaginar un cambio posible en un periodo de tres o seis meses, incluso de un año. Sin embargo, trazar un proyecto de plazo más largo, implica la entrada en juego de múltiples factores desconocidos que pueden desactivar la motivación de la persona. Por ello, se recomienda el establecimiento de objetivos y prioridades dentro de un plan de trabajo diseñado conjuntamente con la persona, para un periodo de tiempo determinado en el corto o medio plazo. Este plan debe responder a un propósito de cambio, de mejora, y no como respuesta a un recurso impuesto como contraprestación. La decisión sobre el camino a recorrer corresponde a la persona, que puede contar con el asesoramiento del profesional.

En este punto conviene recordar que proceso significa idas y venidas. No se trata de un recorrido lineal ni unidireccional ni continuo; ni tampoco replicable para todos los sujetos etiquetados dentro de una misma categoría. Siempre es personalizado, y de ahí que sea ne- 
cesario el trabajo relacional que implica el Trabajo Social. Para ello, es preciso programar encuentros periódicos y frecuentes, la mayoría de ellos planificados con antelación, y en otros momentos serán imprevistos, y requerirán una cierta intervención, cuyo grado de profundidad dependerá de la gravedad de la situación sobrevenida.

Como toda relación entre dos o más personas pasa por una serie de fases, que van desde el conocimiento y reconocimiento mutuo al autoconocimiento del sujeto y de su situación, la identificación de los puntos fuertes y débiles, y el establecimiento del deseo de cambio, el balance de oportunidades y retos. Este primer momento, que coincide con la fase diagnóstica, es la de construcción de la relación de ayuda, convertirse en profesional de referencia. A partir de dicha relación es posible iniciar el proceso de trabajo, con la elaboración de planes y propuestas de acción para un periodo de tiempo, y en su caso, establecer el contrato o acuerdo de trabajo, oral o escrito, en función de los casos, en todo caso explícito, concreto y definido para un periodo de tiempo.

A medida que el proceso se va desarrollando, en la siguiente fase la relación de ayuda se centra en el seguimiento de los compromisos de ambas partes y su grado de realización, así como en la reflexión sobre las experiencias obtenidas. Este aspecto es importante, puesto que el deseo de cambio implícito en toda situación de necesidad, suele enfocar nuevas necesidades y obviar los logros obtenidos. Es por ello recomendable utilizar sistemas de registro de información objetivos, que permitan evidenciar los cambios obtenidos y reforzar los comportamientos que han dado lugar a dichos resultados.

En esta fase, cuando la relación de ayuda se ha consolidado, el profesional tendrá más permeabilidad para dar orientación y consejo en más aspectos que los inicialmente tratados. Y también, en ocasiones, será preciso acometer acciones destinadas a resolver dificultades urgentes preexistentes o sobrevenidas, orientadas a mejorar las condiciones de vida, en los diferentes ámbitos vitales.

Todo proceso tiene un principio y un final, como también los procesos de incorporación social. En la fase final debe realizarse la evaluación de los logros obtenidos, de los aprendizajes extrapolables a otras situaciones y de los obstáculos encontrados y de las formas utilizadas para superarlos. Si en el balance final se encuentran elementos que justifican reiniciar un nuevo proceso, éste daría paso a una nueva secuencia, con la determinación de objetivos y metas. Debemos subrayar que dicha secuencia es un nuevo proceso, con sus límites temporales.

La propuesta del acompañamiento consiste en presentar a la persona una relación de apoyo y ayuda como recurso profesional para orientarle en un proceso de cambio. Se trata, por lo tanto, de ofrecerle un intangible que no garantiza respuestas inmediatas a sus problemas. Es preciso que el trabajador social sea capaz de transmitir, de forma clara y sencilla, en qué consiste el acompañamiento, identificando los elementos clave del proceso. Se le ofrece una relación con un profesional que le orientará durante un periodo, en el análisis de su situación y búsqueda de soluciones alternativas; le apoyará y reforzará en el diseño y desarrollo del plan trazado y le acompañará, a lo largo del proceso, alentando en los momentos difíciles y revisando los logros obtenidos. En esta fase es imprescindible determinar quién es el profesional de referencia sabiendo que la persona responsable del proceso es el propio individuo en proceso de incorporación social.

Una vez aceptado el proceso de acompañamiento comienza la intervención propiamente dicha con la elaboración de un plan de trabajo. En el texto de Funes y Raya se le denomina Plan de Trabajo Compartido, con dicho adjetivo se pretende recordar que la persona es la protagonista del proceso y el plan de trabajo no puede ser impuesto por los Servicios Sociales, como una contraprestación por la prestación económica recibida, sino definido y decidido, cuando menos, de forma conjunta. El plan se caracteriza por estructurar un proceso de trabajo con la persona y ser participativo, en el que ambas partes plantean sus puntos de vista sobre la situación problema y los medios para afrontarla. A partir del análisis conjunto de la situación (o co-diagnóstico) se traza el plan de trabajo, en el que se definen los objetivos, acciones, plazos y responsables de cada hito. Poner en marcha el plan implica ejecutar una o varias de las intervenciones directas o indirectas del Trabajo Social, de acuerdo a la tipología de Cristina de Robertis (Cuadro 2). 


\begin{tabular}{|c|c|}
\hline Intervenciones directas & Intervenciones indirectas \\
\hline $\begin{array}{l}\text { Clarificar-apoyar } \\
\text { Informar ya educar } \\
\text { Persuadir e influir } \\
\text { Controlar-ejercer auto- } \\
\text { ridad } \\
\text { Poner en relación-crear } \\
\text { nuevas oportunidades } \\
\text { Estructurar una rela- } \\
\text { ción de trabajo con el } \\
\text { asistido }\end{array}$ & $\begin{array}{l}\text { Organización-docu- } \\
\text { mentación } \\
\text { Programación y plani- } \\
\text { ficación de interven- } \\
\text { ciones directas } \\
\text { Intervención en el en- } \\
\text { torno del asistido } \\
\text { Colaboración con otros } \\
\text { profesionales } \\
\text { Intervención a nivel de } \\
\text { organismos oficiales }\end{array}$ \\
\hline
\end{tabular}

Cuadro 2. Proceso metodológico de acompañamiento.

Fuente: De Robertis, 1992, 135-201.

La utilización de una u otra depende de la situación concreta y del momento del proceso. Cada profesional conjugará los elementos de acuerdo con su propia «caja de herramientas». En todo caso, todo proceso de incorporación social implica un proceso de cambio. Y ello supone tomar conciencia de la situación de partida, conocer y reconocer cuáles son los ámbitos vitales a trabajar, con qué recursos se cuenta, para poder definir una situación de llegada, determinar qué se desea conseguir.

El concepto de necesidad tiene una acepción de «estado de carencia que lleva implícita la potencialidad de moverse en dirección a su satisfacción» (Ramos, 2003, p. 344). Este es el resorte que permite movilizar a la persona hacia un proceso de cambio. En la fase inicial del proceso será necesario recoger información analizarla e interpretarla con la persona, con el fin de elaborar el plan de trabajo. Esta actividad de conocimiento tiene cuatro características específicas: a) Se trata de un conocimiento ligado a la acción, se busca información útil para el proceso de incorporación; b) Tiene que convertirse en autoconocimiento, la persona debe ser consciente de las implicaciones del diagnóstico y del juicio crítico; c) Analiza y descubre las potencialidades, los aspectos positivos, las capacidades; d) La finalidad es orientar el proceso de cambio no catalogar o categorizar.

La recogida de información se centra en aspectos vitales de la persona, la trayectoria recorrida, sus soportes, todo ello forma parte del co-diagnóstico, en concreto se trata de obtener información sobre elementos personales, que sirvan a la persona a aclararse consigo misma; elementos de su entorno, de convivencia, pertenencia, relación social. Se trata de adoptar una perspectiva holística para la comprensión de la situación de la persona y sus estrategias de futuro.

El acompañamiento, como metodología se basa, en gran medida, en la relación de confianza entre el profesional y la persona usuaria. Eso no significa que deba realizarse de forma quijotesca dentro del servicio. De hecho, como advierten Funes y Raya, el acompañamiento no es una simple relación personalizada entre los dos actores en juego. El Trabajo Social de acompañamiento se enmarca dentro del servicio social o agencia que lo promueve y posibilita. El acompañamiento como forma de trabajo en procesos de cambio con personas en situación de grave dificultad o exclusión desgasta y confronta al profesional con su propia realidad e incertidumbres. Frecuentemente se necesita de contraste, apoyo o refuerzo. Por tanto, el acompañamiento es una metodología, que de alguna manera, debe organizarse para trabajar en equipo.

Formar equipo supone compartir un marco teórico y metodológico sobre la exclusión social; tener una mirada común, o al menos no opuesta, sobre los problemas sociales, sus causas y consecuencias; respeto al trabajo de cada uno y comprensión hacia las razones de los colegas; contrastar las propias opiniones y propuestas y aceptar la revisión por parte del equipo, que en definitiva se orienta al proyecto común de trabajar en clave de acompañamiento. En suma, se trata de querer hacer equipo, por encima de las dificultades.

Funes y Raya aluden a razones de tipo pragmático como: a) La disponibilidad y la flexibilidad para atender la demanda. Esto se posibilita en mayor medida cuando se trabaja en equipo que cuando se trabaja de forma individual. b) Evita la dependencia del proceso en casos de especial dificultad. c) Permite contrastar con otros profesionales las situaciones de dificultad que pueden surgir en la relación de ayuda. En este aspecto, resulta clave recordar el papel que la supervisión de apoyo, como herramienta de Trabajo Social, desempeña en el cuidado del profesional (Fernández, 1997; Hernández, 1999). Valga el siguiente extracto 
como explicación de la importancia del trabajo en equipo en el proceso de acompañamiento:

Si para analizar correctamente una situación necesitamos una cierta distancia y, a la vez, para que la persona se sienta acompañada hemos de practicar la proximidad, parece evidente que necesitamos el contraste, que debemos contar con la posibilidad de discutir a partir de las visiones que otro profesional nos facilite. Es muy fácil contaminarse con las visiones que las personas tienen de sus problemas y dejar de ofrecerles otras aproximaciones, por eso necesitamos de alguien que nos ayude a recuperar la capacidad de observación. Si nos ocupamos de la globalidad, si tenemos en cuenta la totalidad de la persona, es fácil que nos sintamos, o nos hagan sentirnos, responsables únicos de la persona. El equipo ayuda a resituar las responsabilidades compartidas y a limitar las pretensiones. (Funes y Raya, 2001, p. 86).

Además de las razones anteriores, también debemos destacar la suma positiva de conocimientos, habilidades, actitudes que aporta el grupo. El trabajo en equipo se enriquece con lo que cada uno de los miembros es capaz de realizar, de forma específica. Cada profesional ha ido "cargando su mochila» con sus experiencias vitales, su formación complementaria, que se puede poner al servicio del proyecto global. Además, como demuestra la teoría de grupos, el trabajo en equipo permite diseñar y aplicar estrategias colectivas, formas de acción que no serían posible desde un trabajo individual.

La forma de organización de los equipos para trabajar en clave de acompañamiento, deberá realizarse a partir de los elementos disponibles en cada contexto concreto. Es importante establecer con claridad quién es el profesional de referencia, para evitar parcelar la vida de la persona en función de la problemática concreta. Las personas con graves problemas sociales han ventilado su vida en muchos despachos que se han ocupado de parte de sus problemas de forma parcial. Con el acompañamiento se trata de trabajar con la persona desde una visión integral. Por ello es importante establecer qué profesional será el referente de caso. En este aspecto se deberá considerar el marco normativo $^{2}$, por un lado y por otro, aceptar que determinados casos no podrán ser atendidos por un determinado profesional, por razón de territorialidad por ejemplo, si no existe compatibilidad entre ambos. Se ha dicho que el acompañamiento se basa en una relación de confianza y de voluntariedad por parte de la persona usuaria con respecto al servicio. $\mathrm{Y}$, en algunos casos, es posible que la primera condición no se cumpla, puesto que existiera una relación previa profesional-usuario que dificulte la confianza recíproca. El equipo deberá prever formas alternativas de organización.

En el proceso de acompañamiento se contará con el resto de profesionales del equipo de servicios sociales y de la red de recursos del entorno con los que se realizará un trabajo coordinado de desarrollo y seguimiento de las acciones en función de los objetivos establecidos en el plan de incorporación personalizado.

\section{Algunas técnicas que posibilitan el acom- pañamiento}

En el siguiente extracto se recogen una serie de recomendaciones que nos dan idea de algunas técnicas que posibilitan el acompañamiento:

- Poner el énfasis en lo normal, no en lo patológico.

- Evitar la rigidez mental del o la profesional.

- Ir con la verdad por delante.

${ }^{2}$ En el artículo 8d de la ley de Servicios Sociales del País Vasco se establece que «se asignará a cada persona o familia un profesional o una profesional de referencia en el Sistema Vasco de Servicios Sociales, al objeto de garantizar la coherencia de los itinerarios de atención y la coordinación de las intervenciones en los términos contemplados en el artículo 19». Dicho artículo se refiere al procedimiento básico de intervención. En su punto 4, señala que «la responsabilidad para la coordinación del procedimiento recaerá en un profesional o una profesional del Sistema Vasco de Servicios Sociales en los siguientes términos: a) En la fase inicial del procedimiento, la responsabilidad recaerá en una trabajadora o trabajador social del Servicio Social de Base, que actuará como profesional de referencia, salvo que por la naturaleza de la intervención se estime más adecuado que la función de referencia recaiga en otra figura profesional, contando, en su caso, con la colaboración y participación de otras personas profesionales de los Servicios Sociales Municipales». 


\begin{tabular}{|c|c|c|}
\hline Individual/Familiar & Grupal & Comunitario \\
\hline Gestión de caso & Interacción grupal & Trabajo en red \\
\hline $\begin{array}{l}\text { Entrevista } \\
\text { Co-diagnóstico } \\
\text { Contrato } \\
\text { Plan de Trabajo } \\
\text { Evaluación }\end{array}$ & $\begin{array}{l}\text { Dinámicas de grupo } \\
\text { Trabajo grupal }\end{array}$ & $\begin{array}{l}\text { Mapas de recursos } \\
\text { Innovación social } \\
\text { (Trabajo Social 2.0) }\end{array}$ \\
\hline $\begin{array}{l}\text { Habilidades personales y com- } \\
\text { petencias }\end{array}$ & $\begin{array}{l}\text { Espacios de encuentro grupal con } \\
\text { iguales }\end{array}$ & $\begin{array}{l}\text { Participación social en el entor- } \\
\text { no }\end{array}$ \\
\hline \multirow[t]{2}{*}{ Red de apoyo } & \multirow[t]{2}{*}{ Apoyo social } & Entornos inclusivos \\
\hline & & Red social \\
\hline
\end{tabular}

Cuadro 3. Algunas técnicas que posibilitan el acompañamiento.

Fuente: Raya y Caparrós, 2013.

- Hablar mucho e intensamente y amistosamente a intervalos frecuentes con los o las clientes.

- No considerarse infalible.

- Buscar los aspectos positivos de la relación del Trabajo de casos.

- Estar disponible a las llamadas de emergencia.

- Estimular el cambio de aires del o la cliente alejándolo de sus tensiones y conflictos

- Saber ver los avances por escondidos y pequeños que sean, en el caso de que éstos se produzcan.

- Confiar en los o las clientes, lo que ayuda al éxito.

- Emplear el acompañamiento y la paciencia.

- Considerar a las personas desde la honestidad, el afecto, la simpatía, la pulcritud, la puntualidad, la responsabilidad, la estabilidad.

Se trata de una serie de consejos técnicos que da Mary Richmond ${ }^{3}$ para el Trabajo Social de casos. Su relectura, casi un siglo después, recuerda que el acompañamiento forma parte del ADN del Trabajo Social. Sin embargo, el desarrollo y consolidación de los Servicios Sociales, con la normalización de los procedimientos de atención ha hecho olvidar en muchos casos la naturaleza relacional de la intervención del Trabajo Social, ahogando al profesional en la tramitación de expedientes. La metodología del acompañamiento refresca la esencia de la relación profesional puesta al servicio del trabajo de ayuda en un proceso de transformación social, recordando el papel del trabajador social como agente de cambio.

Para cumplir los objetivos de dicho rol, el equipo cuenta con diferentes técnicas de intervención social, conjugando los diferentes niveles metodológicos, como se ve en el Cuadro 3 .

Excede a los objetivos de este artículo explicar los diferentes niveles de intervención. No obstante, consideramos necesario recordar la importancia de trabajar con la persona utilizando diferentes estrategias, en función de los objetivos del plan. Sin olvidar que el trabajo social grupal y comunitario son parte esencial del trabajo social de acompañamiento ${ }^{4}$.

${ }^{3}$ Mario Gaviria, en el prólogo a la edición del libro El Caso Social Individual y en los textos seleccionados de Diagnóstico social, señala que «Mary Richmond da consejos técnicos que, por evidentes y aparentemente simples, son, a veces, olvidados por los profesionales del Trabajo Social». Y tras su enumeración añade: «Todas estas técnicas y características o hábitos de la personalidad deberían intentarse conseguir en el Trabajo Social de Casos.» (Gaviria, 1996, p. 16).

${ }^{4}$ Para mayor profundización en Trabajo Social grupal y acompañamiento puede verse Arija (2012). Sobre la dimensión comunitaria del acompañamiento, González (2011). Por su parte Funes y Raya (2001), aluden a ambas dimensiones. 


\section{Consideraciones finales}

Hasta el momento hemos hablado del acompañamiento como metodología del Trabajo Social para atender a personas en situación o riesgo de exclusión. La aplicación de la metodología implica partir de la premisa de su adecuación para personas con capacidad de tomar decisiones sobre su vida. Esta metodología supone un cambio en la relación entre profesional y usuario; el primero asume un papel de facilitador del proceso y el segundo adopta un papel activo, no de receptor pasivo de ayuda. Este cambio de perspectiva implica también un cambio de rol del profesional, de gestor de prestaciones sociales a generador de recursos, donde el principal recurso es la relación de ayuda, pero también la puesta en valor de los recursos personales con los que cuenta la persona que emprende un proceso de cambio. En la práctica del trabajo social el acompañamiento es una metodología inherente al desarrollo de la profesión, como ha quedado patente en el apartado anterior.

Ahora nos gustaría poder aportar evidencia que ponga de manifiesto el alcance y los resultados que implica el acompañamiento, como metodología de intervención con colectivos con déficits de integración social. En este punto, confluimos con la afirmación realizada por Cristina de Robertis, cuando señala que
Seguramente, la investigación sobre la práctica profesional en este aspecto podría darnos nuevos elementos para comprender la evolución actual de esta técnica profesional, pero lo investigación está aún poco desarrollada en el trabajo social y su función creadora de conocimientos, poco reconocida (De Robertis, 2003).

En los últimos diez años la posición de la disciplina respecto a la investigación ha mejorado, sin embargo tenemos mucho camino por recorrer.

En los estudios sobre metodología de la intervención social en general, y del acompañamiento en particular, sería interesante disponer de evidencia de los resultados obtenidos por diferentes equipos que están interviniendo en la realidad. En este sentido, estamos convencidas de que la falta de evidencia no es tanto por falta de resultados positivos sino por la de su transferencia. En los últimos años se han publicado algunos trabajos con experiencias prácticas (Arjona, 2004 y 2008; Alter, 2008) Sería necesario profundizar en trabajos de investigación que retroalimenten los aprendizajes de la práctica y permita avanzar en el conocimiento disciplinar del trabajo social y su desarrollo profesional, en línea con lo planteado por diferentes autores (Raya, 2009; Giménez, 2012). Ello implica dedicar tiempo a la evaluación y a la sistematización de la experiencia, y tiempo significa dedicación de recursos económicos y humanos.

\section{Referencias bibliográficas}

Aguilar, M. y Llobet, M. (2011). Integralidad, acompañamiento, proximidad, incorporación: el papel de los servicios sociales. En VV.AA., Guía de recomendaciones y líneas de actuación en inclusión social. Madrid: Fundación Luis Vives.

Arija Gisbert, B. (2012). Acompañamiento con grupos en Trabajo Social, Un modelo interfocal para la comprensión y sistematización de la praxis. Cuadernos de Trabajo Social, 25 (2), 427-438.

Arjona, M. (2004). Itinerario de acompañamiento social con familia. Revista Trabajo Social Hoy, $1,35-46$.

Arjona, M. (2008). Estrategias de inclusión social desde el ámbito local. Proyecto de acompañamiento e inclusión social. Servicios Sociales. Ayuntamiento de Parla. Revista Trabajo social hoy, 1, 131-144.

De Robertis, C. (1992). Metodología de la intervención en Trabajo Social. Barcelona: Editorial El Ateneo,

De Robertis, C. (2003). Fundamentos del Trabajo Social. Valencia: Editorial Nau Llibres.

Fernández Barrera, J. (1997). La supervisión en Trabajo social. Buenos Aires: Paidós.

Funes, J. (1995). La incorporación social de las personas con problemas de drogas. Una propuesta conceptual y metodológica pensando en la atención primaria. Vitoria: Gobierno Vasco.

Funes, J. y Raya, E. (2001). El acompañamiento y los procesos de incorporación social, Guía para su práctica. (Documento de Trabajo). Federación Sartu, Dirección de Bienestar Social, Gobierno Vasco. 
Gaviria, M. (1996). Una relectura de Mary E. Richmond en Richmond. M. (1922) El caso social individual y (1917) Diagnóstico Social. Madrid: Talasa.

Giménez, V. (2012). Investigar desde el Trabajo Social: Aprendizajes en I+D en el marco del proyecto INCASS. Revista Atlántida, 4, 49-72.

González, E. (2011). La coordinación, el liderazgo y el trabajo en red para la inclusión activa en el ámbito local. En VVAA., Guía de recomendaciones y líneas de actuación en inclusión social. Madrid: Fundación Luis Vives.

Hernández Aristu, J. (1999). La Supervisión: Calidad de los servicios sociales. Pamplona: Editorial Eunate.

Nogués, L. (2007). El acompañamiento social de familias gitanas con trayectorias de marginación y exclusión residencial. Revista Documentación social, 145,133-152.

Ramos, C. (2003). Las necesidades sociales. Conceptos. Perspectivas de análisis de las necesidades sociales. Problemas sociales y necesidades. En T. Fernández y C. Alemán (eds.). Introducción al Trabajo Social. Madrid: Alianza.

Raya Díez, E. (2009). I+D+i en la intervención social. Revista Española del Tercer Sector, 13, 39-62.

Raya Díez, E. (2010). Aplicaciones de una herramienta para el diagnóstico y la investigación en exclusión social. Documentos de Trabajo Social: Revista de trabajo social y acción social, 48, 117-136.

Raya, E. y Caparrós, N. (2013). Espagne: Le travail social à la recherche d'indicateurs en inclusion sociale. Revue Française de Service Social, 250, 106-116.

Raya Díez, E. y Caparrós Civera, N. (2013). El acompañamiento en los servicios de atención primaria. Documentos de Trabajo inéditos.

VV.AA. (2008). Familias en Exclusión Social Extrema. II Plan de Lucha contra la Exclusión Social de Navarra. Disponible en: http://www.unavarra.es/digitalAssets/180/180401_08-Familias-en-exclusi-n-social-extrema-PDF.pdf (consultado el 20 de junio de 2013). 